\title{
Lack of association between $L E P R$ Lys656Asn or Ser343Ser polymorphisms and cancer susceptibility: A meta-analysis
}

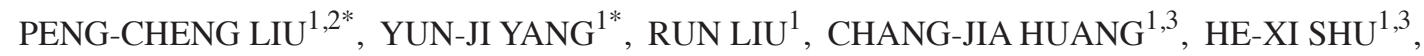 \\ JIN-PENG GONG ${ }^{1,3}$, QUAN-CHI CHEN ${ }^{1,2}$, YONG YANG ${ }^{1}$ and MING CAI $^{1}$ \\ ${ }^{1}$ Department of Orthopedics, Shanghai Tenth People's Hospital, School of Medicine, Tongji University, Shanghai 200072; \\ ${ }^{2}$ Department of First Clinical Medical College, Nanjing Medical University, Nanjing, Jiangsu 210029; \\ ${ }^{3}$ Medical Department, Soochow University, Suzhou, Jiangsu 215123, P.R. China
}

Received June 26, 2014; Accepted July 28, 2014

DOI: $10.3892 /$ br.2014.326

\begin{abstract}
Previous studies have shown conflicting results between the association of leptin receptor ( $L E P R)$ genetic polymorphisms and cancer risk. The frequent $L E P R$ Lys656Asn or Ser343Ser genetic polymorphism has been demonstrated to be functional and may promote genetic susceptibility to cancers. However, the association between the LEPR Lys656Asn or Ser343Ser genetic polymorphism and cancer risk remains to be determined. To improve the understanding of the LEPR Lys656Asn or Ser343Ser genetic polymorphism role in global cancer, a comprehensive meta-analysis was conducted that comprised 2,480 cases and 3,162 controls. The LEPR Lys656Asn or Ser343Ser genetic polymorphism did not significantly affect the cancer risk. In the stratified analysis, there was no significant association of the LEPR Lys656Asn or Ser343Ser variants with any type of cancer under any model. In addition, significantly increased risks were found in the Asian population in heterozygous codominant [odds ratio (OR), 1.24 (1.01-1.53)] and dominant [OR, 1.24 (1.02-1.50)] genetic models. A significantly increased susceptibility to cancer was not found when stratified by study design. There were no significant differences found in genotype method and sample size in cases among the genotypes. These findings indicated a lack of association between LEPR Lys656Asn or Ser343Ser polymorphisms and cancer susceptibility, however, these polymorphisms may increase the cancer susceptibility among the Asian population, particularly in the dominant genetic model. The
\end{abstract}

Correspondence to: Dr Ming Cai, Department of Orthopedics, Shanghai Tenth People's Hospital, School of Medicine, Tongji University, 301 Middle Yanchang Road, Shanghai 200072, P.R. China

E-mail: cmdoctor@tongji.edu.cn

*Contributed equally

Key words: leptin receptor, Lys656Asn, Ser343Ser, cancer, genetic polymorphism, meta-analysis single-nucleotide polymorphism is also suggested to function as a dominant mutation, which requires verification or association with functional studies.

\section{Introduction}

Cancer is one of the leading causes of mortality and has become a worldwide public health problem (1). The exact mechanism of carcinogenesis remains to be fully elucidated (2). Previous studies have indicated that the contribution of genetic variation to cancer development and progression has become clearer $(2,3)$. However, the identification of susceptibility genes is problematic and the majority of the associations have not been replicated due to various problems, such as significant heterogeneity of the disease.

Obesity has been found to be associated with an increased risk of cancer. Leptin (LEP, also known as OB for obese) is an adipocyte-derived hormone that is mainly produced by white adipose tissue to regulate appetite and weight, body metabolism and reproductive functions, together with the leptin receptor (LEPR) (4). The LEP gene, located at chromosome 7q31.3, encodes a $16-\mathrm{kDa}$ protein that has been consistently shown to be associated with endocrinological metabolism (5). Leptin has been previously indicated to contribute to serum insulin levels and the development of type 2 diabetes (6), and to be involved in the pathophysiology of obesity $(7,8)$ and carcinogenesis (9-14). In addition to regulating body weight, leptin also affects reproduction, angiogenesis, hematopoiesis and immune processes (15). There is evidence indicating that leptin may play a critical role in the initiation and progression of human cancers (16).

A number of studies have investigated the possible association between the LEPR Lys656Asn or Ser343Ser genetic polymorphism and cancer risk, but the results have been conflicting (14,17-21). Thus, the association between the LEPR Lys656Asn or Ser343Ser genetic polymorphism and cancer requires further investigation. In an attempt to clarify this inconsistency, all the published hospital and population-based studies prior to June 2014 were combined in a meta-analysis to provide a comprehensive outlook of the role of the $L E P R$ Lys656Asn or Ser343Ser gene by multiple research methods and models. 
In the present study, a comprehensive meta-analysis was performed on previous studies to investigate the association of LEPR Lys656Asn or Ser343Ser genetic polymorphism with all types of cancer, different types of cancer, ethnicities, populations, genotype methods and various types of sample size in cases.

\section{Materials and methods}

Search strategy and data extraction. In the meta-analysis, a comprehensive literature search of the US National Library of Medicine's PubMed database, ISI Web of Knowledge, Medline, Embase and Google Scholar Search (prior to to June 2014) was conducted using the following search terms, including 'leptin receptor,' 'leptin gene receptor,' 'leptin receptor gene,' 'LEPR,' 'Lys656Asn,' 'K656N,' 'rs8179183' or 'Ser343Ser'; 'polymorphisms,' 'variation,' 'mutation' or 'SNP;' 'tumour,' 'tumor,' 'cancer,' 'neoplasm,' 'phyma,' 'oncoma,' 'knub,' 'carcinoma' or 'malignancy;' and the combined phrases in order to obtain all the genetic studies on the association of LEPR Lys656Asn or Ser343Ser genetic polymorphism and cancers. The references of the original or reviewed studies were also examined to identify additional studies. Eligible studies were selected according to the following explicit inclusion criteria: i) A case-control study on the association between the LEPR Lys656Asn or Ser343Ser genetic polymorphism and cancer risk, ii) detailed number of different genotypes for estimating an odds ratio (OR) with 95\% confidence interval (CI), iii) when several publications reported on the same population data, the largest or most complete study was chosen, iv) cases with carcinomas were diagnosed by histopathology and v) animal, case or review studies, abstracts, editorials, studies with incomplete data and studies based on pedigree data were excluded (Fig. 1). For each eligible study, the following information was recorded: First author's name, year of publication, country, ethnicity, type of cancer, genotyping methods, sources of controls, ethnicity of the study population, genotype and allele distributions, and main results of each study.

Statistical analysis. The strength of the association between the LEPR Lys656Asn or Ser343Ser genetic polymorphism and cancer was assessed by using crude OR with $95 \% \mathrm{CI}$. The association between the LEPR Lys656Asn or Ser343Ser genetic polymorphism and cancer risk was examined using the following genetic models: Homozygote co-dominant (CC vs. GG), heterozygote co-dominant (CG vs. GG), dominant genetic (CC/CG vs. GG), recessive genetic (CC vs. CG/GG) and additive genetic (C vs. G) models. Firstly, the Hardy-Weinberg equilibrium (HWE) was checked in the controls for each study. Subsequently a Q test was performed to evaluate the heterogeneity (22). Fixed-effects model was used to pool the data when the $\mathrm{P}$-value of $\mathrm{Q}$ test $\geq 0.05$, otherwise, random-effects model was selected (23). $\mathrm{I}^{2}$ was also used to assess the heterogeneity in the meta-analysis, and heterogeneity existed when $\mathrm{I}^{2}>50 \%$ (24). Sensitivity and subgroup analyses were also performed to explore the reason of heterogeneity. The funnel plot and Egger's test were used to assess the publication bias and $\mathrm{P}<0.05$ was considered to indicate a statistically significant difference (25). All the statistical analyses were performed

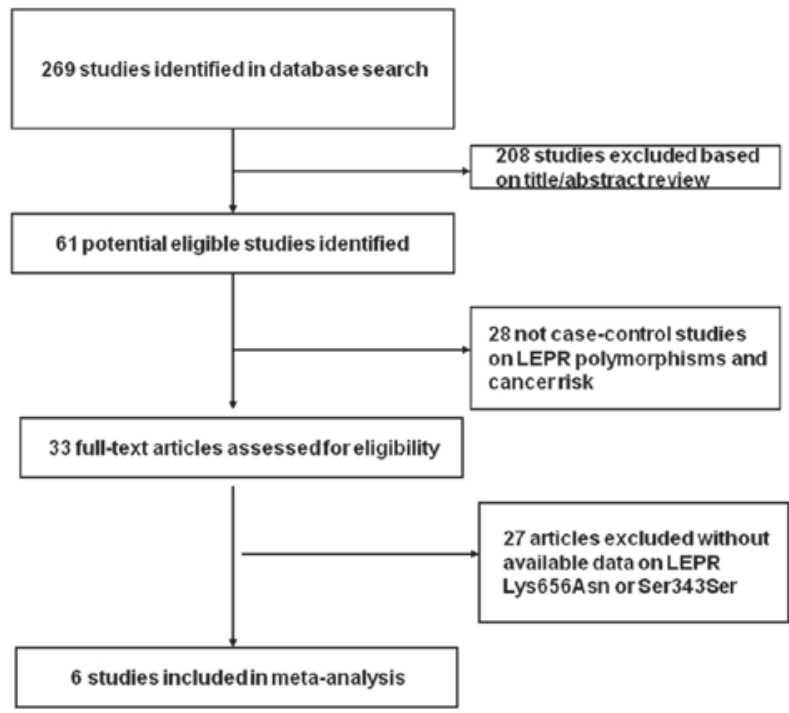

Figure 1. Flow diagram of study identification. $L E P R$, leptin receptor.

using Stata 12.0 software (StataCorp, College Station, TX, USA) and Review Manager 5.2 (The Cochrane Collaboration, The Nordic Cochrane Centre, Copenhagen, Denmark).

\section{Results}

Eligible studies. Overall, eight relevant studies comprising 2,480 cases and 3,162 controls were selected in the meta-analysis $(14,17-21)$. The main characteristics of these studies are shown in Table I. Genotype and allele distributions of LEPR Lys656Asn or Ser343Ser genetic polymorphism among cancer cases and controls and the P-value of HWE in controls are shown in Table I. All the studies were case-control studies, including two breast $(17,19)$, two colorectal (14), two gastric (21), one esophageal (18) and one lung cancer studies (20). Cancers were histological or pathological in the majority of the studies. There were four studies $(14,18,19)$ investigating the Caucasian population and four studies $(17,20,21)$ investigating the Asian population. Population-based controls were carried out in three studies, whereas hospital-based controls were carried out in five studies. All the studies were reported in English. The genotyping methods contained the classic polymerase chain reaction-restriction fragment length polymorphism (PCR-RFLP) assay, PCR-sequencing, Sequenom iPLEX and SNPstream. The sample size in the majority of studies was $>100$ patients. The genotype distributions of the controls were all in agreement with HWE, except for four studies not estimable $(14,19,20)$.

Meta-analysis. Overall, as shown in Table II, the LEPR Lys656Asn or Ser343Ser genetic polymorphism did not significantly affect the risk of cancer when all the eligible studies were pooled into the meta-analysis. When the four studies that the genotype distributions of the controls were not in agreement with HWE were excluded, a significant association was not observed in any genetic model. In all the genetic models, all the P-values of the Q test were $>0.05$ and $\mathrm{I}^{2}$ values were $<50 \%$. The sensitivity analysis was performed by deleting one single 
Table I. Characteristics of the studies included in the meta-analysis.

\begin{tabular}{|c|c|c|c|c|c|c|c|c|c|c|}
\hline Author & Year & Country & Ethnicity & $\begin{array}{l}\text { Cancer } \\
\text { type }\end{array}$ & $\begin{array}{l}\text { Cases/ } \\
\text { controls }\end{array}$ & $\begin{array}{c}\text { Source of } \\
\text { controls }\end{array}$ & $\begin{array}{l}\text { Genotype } \\
\text { method }\end{array}$ & $\begin{array}{l}\text { Polymor- } \\
\text { phisms }\end{array}$ & $\begin{array}{l}\text { P-value of } \\
\text { HWE in } \\
\text { controls }\end{array}$ & (Refs.) \\
\hline Woo et al & 2006 & Korea & Asian & Breast & $45 / 45$ & HB & PCR-sequencing & $\mathrm{K} 656 \mathrm{~N}$ & 0.632 & (17) \\
\hline Chia et al & 2007 & USA & Caucasian & Colorectal & $157 / 191$ & HB & PCR-sequencing & $\begin{array}{l}\text { K656N, } \\
\text { Ser343Ser }\end{array}$ & - & (14) \\
\hline $\begin{array}{l}\text { Doecke } \\
\text { et al }\end{array}$ & 2008 & Australia & Caucasian & Esophageal & $774 / 1352$ & $\mathrm{~PB}$ & $\begin{array}{l}\text { Sequenom } \\
\text { iPLEX }\end{array}$ & $\mathrm{K} 656 \mathrm{~N}$ & 0.718 & (18) \\
\hline Teras et al & 2009 & USA & Caucasian & Breast & $641 / 650$ & $\mathrm{~PB}$ & SNPstream & K656N & - & (19) \\
\hline Li et al & 2012 & China & Asian & Lung & $744 / 832$ & $\mathrm{~PB}$ & PCR-RFLP & $\mathrm{K} 656 \mathrm{~N}$ & $<0.05^{\mathrm{a}}$ & (20) \\
\hline Kim et al & 2012 & Korea & Asian & Gastric & $48 / 48$ & HB & PCR-RFLP & $\begin{array}{l}\text { K656N, } \\
\text { Ser343Ser }\end{array}$ & $\begin{array}{l}0.703 \\
0.644\end{array}$ & (21) \\
\hline
\end{tabular}

${ }^{a}$ Not in agreement with HWE. HWE, Hardy-Weinberg equilibrium; HB, hospital-based; PCR, polymerase chain reaction; PB, population-based; RFLP, restriction fragment length polymorphism.

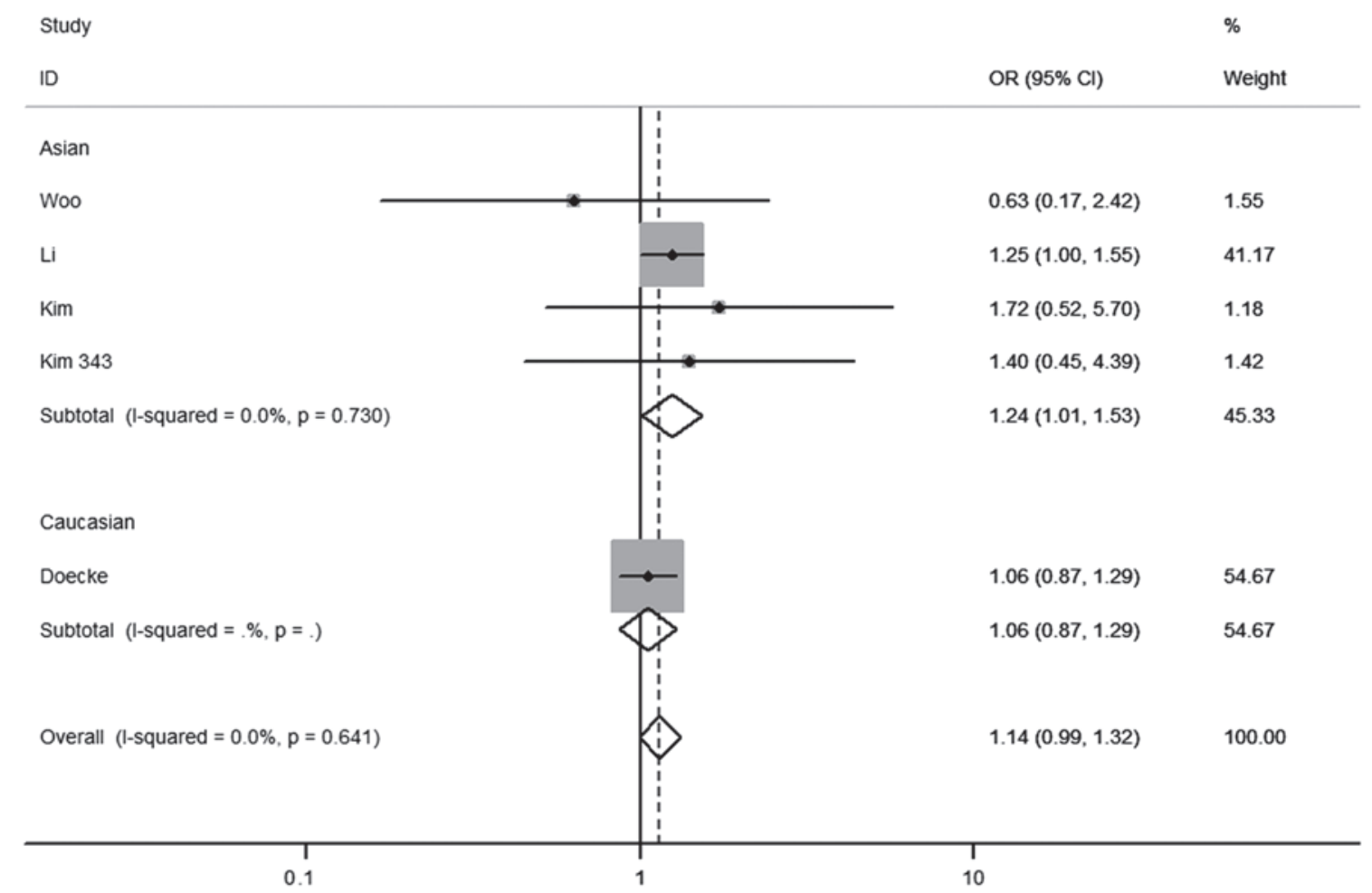

Figure 2. Subgroup analysis of the association between leptin receptor Lys656Asn or Ser343Ser polymorphism and cancer risk by ethnicity (CG vs. GG) (fixed-effects model). The overall OR is shown. The OR of each study is marked with a grey square. The \% weight of OR is indicated by a shadow. The overall OR is indicated by diamond. OR, odds ratio; CI, confidence interval.

study from the overall pooled analysis each time to assess the influence of the removed data. However, the results revealed that no studies changed the between-study heterogeneities.

The effects of the LEPR Lys656Asn or Ser343Ser genetic polymorphisms were evaluated according to specific types of cancer, different ethnicities, different sources of controls, different detection methods and different sample sizes in cases. As shown in Table II, the LEPR Lys656Asn or Ser343Ser genetic polymorphisms were found to not significantly affect the risk of any type of cancer in any genetic model tested.
In the stratified analysis by ethnicity, significantly increased risks were found in the Asian population in the heterozygous co-dominant $[\mathrm{OR}=1.24$ (1.01-1.53)] (Fig. 2) and dominant genetic models [OR=1.24 (1.02-1.50)] (Fig. 3). For the Caucasian population, no significant associations were observed in any genetic model tested. According to the source of controls, a significant association was not observed in any genetic model in population- or hospital-based studies. Regarding the detection method, signification effects in dominant and additive genetic models were observed in the PCR-RFLP subgroup. 


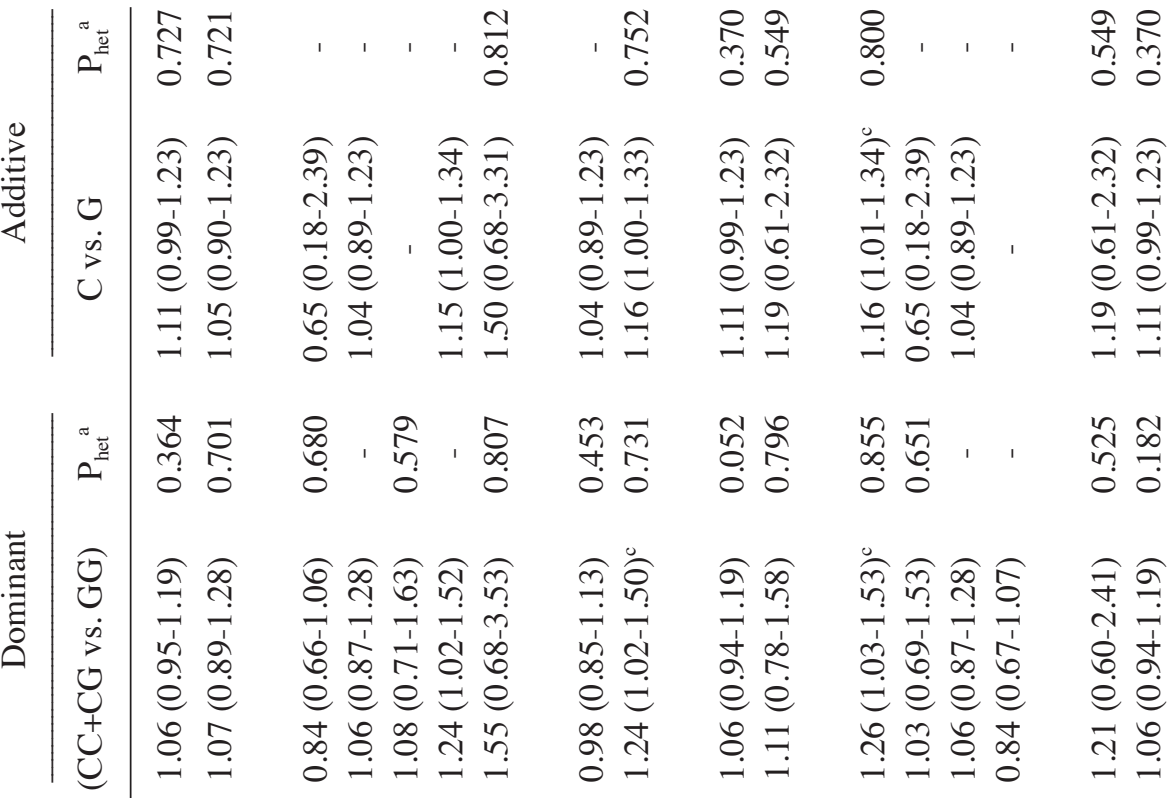

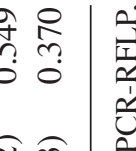

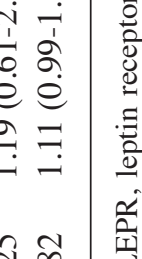

$\dot{\Delta}$

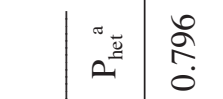

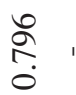

仓ิ

, $\frac{\widehat{F}}{\frac{1}{6}}, \frac{\dot{J}}{\dot{0}}$

守

각

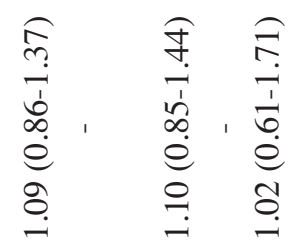

点

己

के ฮิ.

ํ. 일

b

e

ㄷํ은

范

.

$\rightarrow$

تै

邻

, 유 꼬ำ

సิ nิ ڤึ

$\bar{b}$

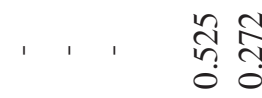

ำ

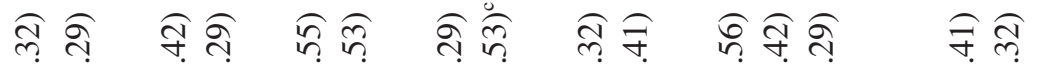
वं के

iT 19

$\rightarrow-1$

尚

돈

$e$

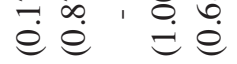

क.

$\dot{e}=$

$\dot{e} \dot{e}$

$\stackrel{e}{=} \stackrel{0}{e}$

$\pm 0$

ชె.

욤

$\exists \vec{\imath}$

ำ

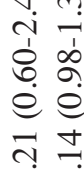

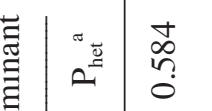

+
$\infty$
$n$
0

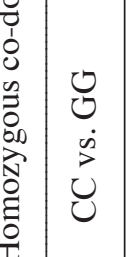

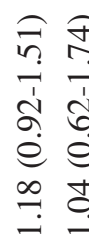

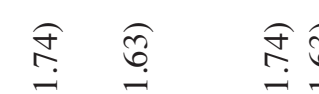

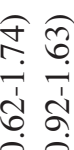

กิ

तิ

¿ำ

$\stackrel{\infty}{=}$

-

$\frac{n}{2}$

\section{要|}

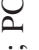



min

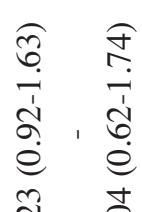

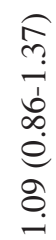

然 


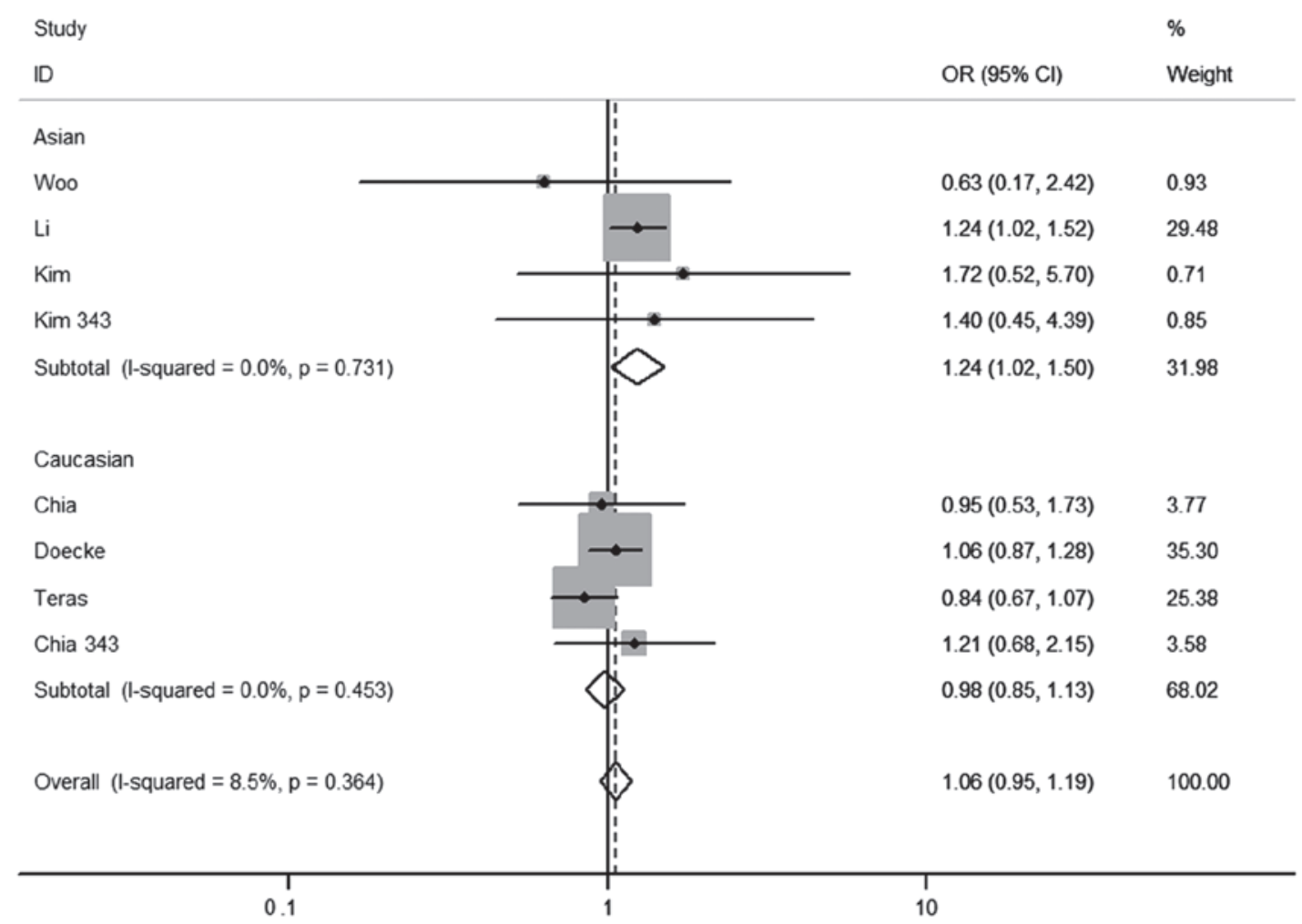

Figure 3. Subgroup analysis of the association between leptin receptor Lys656Asn or Ser343Ser polymorphism and cancer risk by ethnicity (CC and CG vs. GG) (fixed-effects model). The overall OR is shown. The OR of each study is marked with a grey square. The \% weight of OR is indicated by a shadow. The overall OR is indicated by diamond. OR, odds ratio; CI, confidence interval.

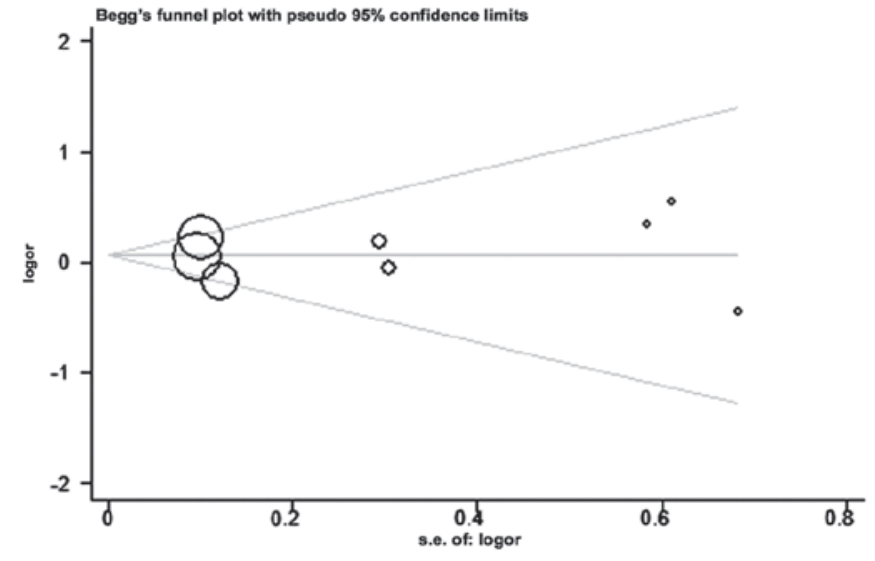

Figure 4. Begg's funnel plot of leptin receptor Lys656Asn or Ser343Ser polymorphism and cancer risk for CC and CG vs. GG contrast model. OR, odds ratio; SE, standard error.

According to the sample size in cases, a significant association was not observed in any genetic model in small $(<100)$ or big $(\geq 100)$ sample studies.

Publication bias. The Begg's funnel plot and Egger's test were performed to assess the publication bias. The shape of the funnel plots did not reveal any evidence of clear asymmetry in the overall meta-analysis (Fig. 4). Egger's test was used to provide statistical evidence of funnel plot symmetry. The results did not present any clear evidence of publication bias (CC vs. GG, P=N/A (not applicable); $\mathrm{CG}$ vs. $\mathrm{GG}, \mathrm{P}=0.891$;
$\mathrm{CC} / \mathrm{CG}$ vs. $\mathrm{GG}, \mathrm{P}=0.933$; $\mathrm{CC}$ vs. $\mathrm{CG} / \mathrm{GG}, \mathrm{P}=\mathrm{N} / \mathrm{A}$; and $\mathrm{C}$ vs. $\mathrm{G}, \mathrm{P}=0.926)$.

\section{Discussion}

The present meta-analysis of eight studies involving 2,480 cases and 3,162 controls was conducted in order to yield a valid conclusion concerning the potential association between the LEPR Lys656Asn or Ser343Ser genetic polymorphism and cancer risk. Indications from epidemiological studies have shown that overweight and obesity may be factors associated with the increased risk of endometrium, kidney, colon and gallbladder cancers in females and breast cancer in postmenopausal females (26), and increased mortality rates for cancers at multiple specific sites (27). Polymorphism-associated low enzyme activity may cause the reduction of conjugation and thus the reduced elimination of oxidative intermediates radicals and electrophiles, resulting in the production of increased carcinogenic substrates rather than detoxification. Polymorphisms in LEPR may therefore influence carcinogen levels and potentially play a role in carcinogenesis. However, studies focusing on the association of the LEPR Lys656Asn or Ser343Ser genetic polymorphism with cancer susceptibility have had controversial conclusions $(14,17-21)$. This indicates limitations in the studies, including ethnical differences, small sample sizes and research methodology. Meta-analysis is known to be a powerful tool for summarizing the results from various studies by generating a single estimate of the major effect with an augmented precision. 
In the present analysis, the pooled effects for all the genetic model comparisons indicated no significant association between the LEPR Lys656Asn or Ser343Ser genetic polymorphism and any cancer risk. Furthermore, it was found that for the Asian population, significant associations were observed in heterozygous co-dominant and dominant genetic models, whereas the Asian population with the CG genotype had a higher cancer risk compared to the Caucasian population. Inconsistencies between the two ethnicities can be explained by the possibility that different ethnic groups experience multiple lifestyle and environmental factors. Different genotype and/or allele frequencies of this locus polymorphism that are present in different populations may result in various degrees of cancer susceptibility. In the present meta-analysis, consistent results were observed between hospital- and population-based studies, but it is still believed that controls in population-based studies are more representative of the general population compared to the controls from hospital-based studies. Several factors, such as environmental factors and genetic backgrounds, may also contribute to the discrepancy.

There were certain limitations in the meta-analysis. Firstly, the sample size for any type of cancer investigated was not sufficiently large, which could increase the probability of false-positive or false-negative results. Therefore, it may be difficult to obtain a complete conclusion if the number of included studies in the subgroup was limited. In addition, the studies involved in the different ethnicities were warranted to estimate the effects of this functional polymorphism on cancer risk. Secondly, as the original data from the eligible studies was not available, evaluating the roles of specific environmental and lifestyle factors, such as diet, alcohol consumption and smoking status, in developing cancer was difficult. Thirdly, the influence of bias in the present analysis could not be completely excluded as positive results are published much quicker than studies with 'negative' results.

In conclusion, the present meta-analysis indicated that the LEPR Lys656Asn or Ser343Ser genetic polymorphism did not significantly affect the risk of cancer, but may increase the susceptibility of cancers in the Asian population in the dominant genetic model. This also suggests that the SNP functions as a dominant mutation, which requires verification or association with functional studies. Large well-designed epidemiological studies are also required to validate these findings.

\section{Acknowledgements}

The authors gratefully acknowledge the support of the subjects who participated in the present study. The study was partly supported by the Natural Science Foundation of Shanghai, China (grant no. 14ZR1432600).

\section{References}

1. Siegel R, Naishadham D and Jemal A: Cancer statistics, 2012. CA Cancer J Clin 62: 10-29, 2012.

2. Wright ME, Peters U, Gunter MJ, et al: Association of variants in two vitamin e transport genes with circulating vitamin e concentrations and prostate cancer risk. Cancer Res 69: 1429-1438, 2009.

3. Cheung WY and Liu G: Genetic variations in esophageal cancer risk and prognosis. Gastroenterol Clin North Am 38: 75-91, 2009.
4. Friedman JM and Halaas JL: Leptin and the regulation of body weight in mammals. Nature 395: 763-770, 1998.

5. Unger RH, Zhou YT and Orci L: Regulation of fatty acid homeostasis in cells: novel role of leptin. Proc Natl Acad Sci USA 96: 2327-2332, 1999.

6. Lakka HM, Oksanen L, Tuomainen TP, Kontula K and Salonen JT: The common pentanucleotide polymorphism of the 3'-untranslated region of the leptin receptor gene is associated with serum insulin levels and the risk of type 2 diabetes in non-diabetic men: a prospective case-control study. J Intern Med 248: 77-83, 2000.

7. Lönnqvist F,Arner P, Nordfors L and Schalling M: Overexpression of the obese (ob) gene in adipose tissue of human obese subjects. Nat Med 1: 950-953, 1995.

8. Yiannakouris N, Yannakoulia M, Melistas L, Chan JL, Klimis-Zacas D and Mantzoros CS: The Q223R polymorphism of the leptin receptor gene is significantly associated with obesity and predicts a small percentage of body weight and body composition variability. J Clin Endocrinol Metab 86: 4434-4439, 2001.

9. Snoussi K, Strosberg AD, Bouaouina N, Ben Ahmed S, Helal AN and Chouchane L: Leptin and leptin receptor polymorphisms are associated with increased risk and poor prognosis of breast carcinoma. BMC Cancer 6: 38, 2006.

10. Liu CL, Chang YC, Cheng SP, et al: The roles of serum leptin concentration and polymorphism in leptin receptor gene at codon 109 in breast cancer. Oncology 72: 75-81, 2007.

11. Han CZ, Du LL, Jing JX, et al: Associations among lipids, leptin, and leptin receptor gene Gin223Arg polymorphisms and breast cancer in China. Biol Trace Elem Res 126: 38-48, 2008.

12. Ribeiro R, Vasconcelos A, Costa S, et al: Overexpressing leptin genetic polymorphism (-2548 G/A) is associated with susceptibility to prostate cancer and risk of advanced disease. Prostate 59: 268-274, 2004

13. Ribeiro R, Araújo AP, Coelho A, et al: A functional polymorphism in the promoter region of leptin gene increases susceptibility for non-small cell lung cancer. Eur J Cancer 42: 1188-1193, 2006.

14. Chia VM, Newcomb PA, Lampe JW, et al: Leptin concentrations, leptin receptor polymorphisms, and colorectal adenoma risk. Cancer Epidemiol Biomarkers Prev 16: 2697-2703, 2007.

15. Loffreda S, Yang SQ, Lin HZ, et al: Leptin regulates proinflammatory immune responses. FASEB J 12: 57-65, 1998.

16. Russo VC, Metaxas S, Kobayashi K, Harris M and Werther GA: Antiapoptotic effects of leptin in human neuroblastoma cells. Endocrinology 145: 4103-4112, 2004.

17. Woo HY, Park H, Ki CS, Park YL and Bae WG: Relationships among serum leptin, leptin receptor gene polymorphisms, and breast cancer in Korea. Cancer Lett 237: 137-142, 2006.

18. Doecke JD, Zhao ZZ, Stark MS, et al; Australian Cancer Study: Single nucleotide polymorphisms in obesity-related genes and the risk of esophageal cancers. Cancer Epidemiol Biomarkers Prev 17: 1007-1012, 2008.

19. Teras LR, Goodman M, Patel AV, et al: No association between polymorphisms in LEP, LEPR, ADIPOQ, ADIPOR1, or ADIPOR2 and postmenopausal breast cancer risk. Cancer Epidemiol Biomarkers Prev 18: 2553-2557, 2009.

20. Li Y, Geng J, Wang Y, et al: The role of leptin receptor gene polymorphisms in determining the susceptibility and prognosis of NSCLC in Chinese patients. J Cancer Res Clin Oncol 138: 311-316, 2012.

21. Kim EY, Chin HM, Park SM, et al: Susceptibility of gastric cancer according to leptin and leptin receptor gene polymorphisms in Korea. J Korean Surg Soc 83: 7-13, 2012.

22. DerSimonian R and Laird N: Meta-analysis in clinical trials. Control Clin Trials 7: 177-188, 1986.

23. Mantel $\mathrm{N}$ and Haenszel W: Statistical aspects of the analysis of data from retrospective studies of disease. J Natl Cancer Inst 22: 719-748, 1959.

24. Higgins JP, Thompson SG, Deeks JJ and Altman DG: Measuring inconsistency in meta-analyses. BMJ 327: 557-560, 2003.

25. Egger M, Davey Smith G, Schneider M and Minder C: Bias in meta-analysis detected by a simple, graphical test. BMJ 315: 629-634, 1997.

26. Bianchini F, Kaaks R and Vainio H: Overweight, obesity, and cancer risk. Lancet Oncol 3: 565-574, 2002.

27. Calle EE, Rodriguez C, Walker-Thurmond $\mathrm{K}$ and Thun $\mathrm{MJ}$ : Overweight, obesity, and mortality from cancer in a prospectively studied cohort of U.S. adults. N Engl J Med 348: 1625-1638, 2003. 